\title{
The Relevance of High Pulse Pressure and Renal Function in Patients with Chronic Kidney Disease: Analysis for each Stage of Chronic Kidney Disease
}

Eiji Kose $^{1^{\star}}$, Taesong An ${ }^{2}$ and Akihiko Kikkawa ${ }^{2}$

${ }^{1}$ Department of Pharmacotherapy, School of Pharmacy, Nihon University, 7-7-1 Narashinodai, Funabashi-shi, Chiba 274-8555, Japan, ${ }^{2}$ Department of Pharmacy, Yokosuka Kyousai Hospital, 1-16 Yonegahamadohri, Yokosuka-shi, Kanagawa 238-8588, Japan.

\begin{abstract}
Background: In our previous study, we showed that high pulse pressure (PP) is associated with decreased renal function in chronic kidney disease (CKD) patients. In recent years, there were a few reports that $\mathrm{CKD}$ stage classification focused on glomerular filtration rate, which is associated with the occurrence of cardiovascular disease, deterioration of renal prognosis, and life prognosis. We aim to examine the relationship between increased PP and renal function according to each CKD stage classification.
\end{abstract}

Methods: The present study includes 104 participants with CKD (stage G3a-G5) who visited the Nephrology Medicine Department of Yokosuka Kyousai Hospital between September 2006 and October 2011. The participants were categorized on the basis of PP: $\geq 65 \mathrm{mmHg}$ was the High PP group, and $<65 \mathrm{mmHg}$ was the Low PP group. We compared the two groups with regard to patient background characteristics, laboratory data from the baseline, and12 months later.

Results: Renal function deteriorated between the baseline and 12 months later at CKD stage G4-G5 in both, the Low and High PP groups; however, there were no significant differences at CKD stage G3a-G3b in both the groups. Changes in renal function at CKD stage G4-G5 in the Low PP group and High PP group were compared for one year from the baseline. $\triangle \mathrm{BUN}, \triangle \mathrm{SCr}$, and $\triangle \mathrm{eGFR}$ were worsened in the High PP group compared to the Low PP group.

Conclusions: Decrease in renal function may be reflected in the advanced CKD stage in which PP has increased.

\section{Introduction}

The prevalence of chronic kidney disease (CKD) is steadily increasing. In Japan, the number of patients with CKD is approximately $13,300,000$ or $13 \%$ of the adult population [1]. Diseases such as diabetes mellitus, hypertension, and obesity, and smoking are known contributors to the progression of CKD or onset of arteriosclerosis $[2,3]$ and increase the risk of cardiovascular disease (CVD) [4]. The Physician's Health Study showed that increase in total cholesterol (TC) and non-high-density lipo cholesterol (non-HDL-C), and decrease in HDL-C were risk factors for the onset of CKD in approximately 4,500 healthy individuals [5]. Therefore, it is extremely important to manage lifestyle that causes arteriosclerosis.

Ankle-brachial index (ABI) and pulse wave velocity (PWV) are useful indicators of arteriosclerosis, which are also associated with renal dysfunction [6]. Abnormally high systolic blood pressure (SBP) impairs endothelial function, and can lead to atherosclerosis and sclerosis of the aorta [7]. Pulse pressure (PP), the difference between SBP and diastolic blood pressure (DBP), is also used as an index of arteriosclerosis [8]. ABI or PWV can only be assessed at medical facilities because it requires special equipment; however, PP can be easily measured at clinics or at home. Because PP is a convenient indicator of arteriosclerosis, it is important to understand the association between PP and renal dysfunction. A previous report showed that high PP was associated with decrease in renal function in CKD patients [9]. In recent years, a few reports have shown that CKD stage classification, focusing on glomerular filtration rate (GFR), is associated with the occurrence of CVD, deterioration of renal prognosis, and life prognosis $[2,10]$. In the present study, we examine the relationship between high PP and renal function according to each CKD stage classification.

Int J Clin Pharmacol Pharmacother

ISSN: 2456-3501

\section{Materials and Methods}

\section{Participants}

In the present study, we retrospectively investigated consecutive patients who visited the Nephrology Medicine Department of Yokosuka Kyousai Hospital between September 2006 and October 2011. In total, our study included 104 participants with CKD (stage G3a-G5) who were diagnosed with hyperlipidemia and commenced on high potency statins. The average normal PP is $50 \mathrm{mmHg}$, and the risk of CVD increases when PP is $\geq 65 \mathrm{mmHg}$ [11]. The participants were categorized on the basis of their PP: $\geq 65 \mathrm{mmHg}$ was the High PP group, and $\mathrm{PP}<65 \mathrm{mmHg}$ was the Low PP group.

\section{Investigation items}

Data regarding the participants' basic information were collected from their medical records at baseline and 12 months later, as appropriate. This included their age, gender, body weight (BW), body mass index (BMI), smoking history, comorbidity (e.g., diabetes mellitus, hypertension). Laboratory data, including the levels of SBP, DBP, aspartate aminotransferase (AST), alanine aminotransferase (ALT), serum uric acid (SUA), blood urea nitrogen (BUN), serum 'Corresponding Author: Prof. Eiji Kose, Department of Pharmacotherapy, School of Pharmacy, Nihon University, 7-7-1 Narashinodai, Funabashi-shi, Chiba 274-8555, Japan, Tel: +81-47-465-2096, Fax: +81-47-465-2096; E-mail: kose.eiji@nihon-u.ac.jp

Citation: Kose E, An T, Kikkawa A (2018) The Relevance of High Pulse Pressure and Renal Function in Patients with Chronic Kidney Disease: Analysis for each Stage of Chronic Kidney Disease. Int J Clin Pharmacol Pharmacother 3: 137. doi: https://doi.org/10.15344/2456-3501/2018/137

Copyright: @ $\odot 2018$ Kose et al. This is an open-access article distributed under the terms of the Creative Commons Attribution License, which permits unrestricted use, distribution, and reproduction in any medium, provided the original author and source are credited. 
Citation: Kose E, An T, Kikkawa A (2018) The Relevance of High Pulse Pressure and Renal Function in Patients with Chronic Kidney Disease: Analysis for each Stage of Chronic Kidney Disease. Int J Clin Pharmacol Pharmacother 3: 137. doi: https://doi.org/10.15344/2456-3501/2018/137

Page 2 of 5

creatinine (SCr), creatinine clearance (Ccr), glomerular filtration rate (eGFR), TC, high-density lipoprotein cholesterol (HDL-C), lowdensity lipoprotein cholesterol (LDL-C), triglyceride (TG), albumin $(\mathrm{Alb})$, serum potassium $(\mathrm{K})$, hemoglobin $(\mathrm{Hb})$, hematocrit $(\mathrm{Hct})$, and glycohemoglobin (HbAlc). The baseline was defined as the time to start pharmacotherapy for dyslipidemia. Changes in BUN, Scr, Ccr, eGFR at baseline and 12 months in CKD stages G3a-G3b and CKD stage G4-G5 between two groups were compared.

\section{Statistical Analysis}

All statistical analyses were performed using JMP ${ }^{\circledR}$ Pro (Version 13 , SAS Institute Inc., Cary, NC, USA). Results are presented as mean \pm standard deviation (SD). A p value $<0.05$ was considered statistically significant. We used the following statistical methods depending on the type of data. Mann-Whitney U test, t-test, Wilcoxon signed-rank test, chi-square test, and Fisher's exact test were used to analyze the differences between groups.

\begin{tabular}{|c|c|c|}
\hline Characteristics & $\begin{array}{l}\text { stage } G 3 a-G 3 b \\
\quad(n=58)\end{array}$ & $\begin{array}{l}\text { stage G4-G5 } \\
\quad(\mathrm{n}=46)\end{array}$ \\
\hline Age $(y)$ & $65.9 \pm 11.0$ & $68.5 \pm 10.8$ \\
\hline \multicolumn{3}{|l|}{ Gender n, (\%) } \\
\hline Male & $38(65.5)$ & $24(52.2)$ \\
\hline Female & $20(35.5)$ & $22(47.8)$ \\
\hline Body weight (kg) & $64.0 \pm 13.7$ & $60.1 \pm 11.9$ \\
\hline Body mass Index $\left(\mathrm{kg} / \mathrm{m}^{2}\right)$ & $24.4(21.9-26.2)$ & $23.3 \pm 5.8$ \\
\hline Smoking history $\mathrm{n},(\%)$ & $26(44.8)$ & $25(54.3)$ \\
\hline \multicolumn{3}{|l|}{ Comorbidity $\mathrm{n},(\%)$} \\
\hline Diabetes Mellitus & $20(34.5)$ & $18(39.1)$ \\
\hline Hypertension & $40(70.0)$ & $38(82.6)$ \\
\hline \multicolumn{3}{|l|}{ Clinical laboratory data } \\
\hline $\mathrm{SBP}(\mathrm{mmHg})$ & $131.8 \pm 16.0$ & $135.8 \pm 16.9$ \\
\hline DBP (mmHg) & $77.6 \pm 12.4$ & $72.9 \pm 10.2$ \\
\hline $\mathrm{PP}(\mathrm{mmHg})$ & $58.2 \pm 14.7$ & $62.8 \pm 14.6$ \\
\hline AST (IU/L) & $26.2 \pm 15.6$ & $20.4 \pm 10.0$ \\
\hline ALT (IU/L) & $22.7 \pm 16.7$ & $15.2 \pm 6.2$ \\
\hline SUA (mg/dL) & $7.0 \pm 1.4$ & $7.4 \pm 1.6$ \\
\hline BUN (mg/dL) & $21.9 \pm 6.1$ & $40.9 \pm 14.8$ \\
\hline $\mathrm{SCr}(\mathrm{mg} / \mathrm{dL})$ & $1.2 \pm 0.3$ & $3.1 \pm 1.4$ \\
\hline $\mathrm{Ccr}(\mathrm{mL} / \mathrm{min})$ & $53.8 \pm 17.4$ & $19.9 \pm 9.3$ \\
\hline $\mathrm{eGFR}\left(\mathrm{mL} / \mathrm{min} / 1.73 \mathrm{~m}^{2}\right)$ & $45.2 \pm 9.1$ & $17.1 \pm 6.7$ \\
\hline $\mathrm{TC}(\mathrm{mg} / \mathrm{dL})$ & $259.1 \pm 95.8$ & $243.5 \pm 52.5$ \\
\hline $\mathrm{HDL}-\mathrm{C}(\mathrm{mg} / \mathrm{dL})$ & $51.0 \pm 12.5$ & $49.3 \pm 15.5$ \\
\hline LDL-C (mg/dL) & $158.7 \pm 73.8$ & $144 \pm 43$ \\
\hline $\mathrm{TG}(\mathrm{mg} / \mathrm{dL})$ & $200.4 \pm 128.8$ & $196.9 \pm 91.1$ \\
\hline Alb (g/dL) & $3.6 \pm 0.9$ & $3.6 \pm 0.5$ \\
\hline $\mathrm{K}(\mathrm{mEq} / \mathrm{L})$ & $4.3 \pm 0.5$ & $4.6 \pm 0.6$ \\
\hline $\mathrm{Hb}(\mathrm{g} / \mathrm{dL})$ & $13.2 \pm 2.0$ & $10.7 \pm 1.6$ \\
\hline $\mathrm{Ht}(\%)$ & $38.5 \pm 6.7$ & $32.1 \pm 6.1$ \\
\hline HbAlc (NGSP) (\%) & $6.4 \pm 1.0$ & $6.2 \pm 0.9$ \\
\hline
\end{tabular}

Table 1: Demographics of participants both CKD stage G3a-G3b and G4-G5.

Values are mean \pm standard deviation where appropriate.

\section{Ethics Regulation}

This retrospective study using medical records was conducted with the approval of the Yokosuka Kyousai Hospital ethics committee (Approval number: 12-10) and complied with the Declaration of Helsinki and the Ethical Guidelines for Clinical Research.

\section{Results}

\section{Descriptive analysis}

Table 1 summarizes the baseline demographics of the participants for both CKD stage G3a-G3b, and G4-G5. We enrolled 104 participants during the study period: 58 participants with CKD stage G3a-G3b including 38 males and 20 females, with a mean age of 65.9 years and 46 participants with CKD stage G4-G5 including 24 males and 22 females with a mean age of 68.5 years.

\begin{tabular}{|c|c|c|c|}
\hline Characteristics & $\begin{array}{c}\text { Low PP } \\
\text { group } \\
(\mathrm{n}=42)\end{array}$ & $\begin{array}{l}\text { High PP } \\
\text { group } \\
(\mathrm{n}=16)\end{array}$ & $\mathrm{p}$ value \\
\hline Age (y) & $64.0 \pm 11.5$ & $69.6 \pm 8.4$ & 0.0833 \\
\hline Gender n (\%) & & & 0.7654 \\
\hline Male & $28(66.7 \%)$ & $10(62.5 \%)$ & \\
\hline Female & $14(33.3 \%)$ & $6(37.5 \%)$ & \\
\hline Body weight $(\mathrm{kg})$ & $64.3 \pm 13.7$ & $68.1 \pm 13.9$ & 0.3807 \\
\hline Body mass Index $\left(\mathrm{kg} / \mathrm{m}^{2}\right)$ & $24.6 \pm 3.4$ & $27.0 \pm 7.3$ & 0.3855 \\
\hline Smoking history $\mathrm{n}(\%)$ & $17(44.7)$ & $9(60.0)$ & 0.3167 \\
\hline \multicolumn{4}{|l|}{ Comorbidity } \\
\hline Diabetes Mellitus n (\%) & $6(37.5)$ & $14(33.3)$ & 0.7654 \\
\hline Hypertension $\mathrm{n}(\%)$ & $12(75.0)$ & $28(66.7)$ & 0.5398 \\
\hline \multicolumn{4}{|l|}{ Clinical laboratory data } \\
\hline $\mathrm{SBP}(\mathrm{mmHg})$ & $126.2 \pm 13.4$ & $147.0 \pm 12.6$ & $<.0001$ \\
\hline $\mathrm{DBP}(\mathrm{mmHg})$ & $76.1 \pm 10.5$ & $73.2 \pm 10.8$ & 0.0677 \\
\hline AST (IU/L) & $28.7 \pm 17.1$ & $25.8 \pm 14.7$ & 0.3507 \\
\hline $\operatorname{ALT}(\mathrm{IU} / \mathrm{L})$ & $26.7 \pm 16.3$ & $18.3 \pm 7.7$ & 0.0228 \\
\hline SUA (mg/dL) & $6.9 \pm 1.4$ & $7.5 \pm 1.5$ & 0.3935 \\
\hline BUN (mg/dL) & $19.5 \pm 6.7$ & $23.8 \pm 8.5$ & 0.0430 \\
\hline $\mathrm{SCr}(\mathrm{mg} / \mathrm{dL})$ & $1.1 \pm 0.3$ & $1.3 \pm 0.4$ & 0.2437 \\
\hline $\operatorname{Ccr}(\mathrm{mL} / \mathrm{min})$ & $58.4 \pm 23.4$ & $50.8 \pm 15.7$ & 0.2542 \\
\hline eGFR $\left(\mathrm{mL} / \mathrm{min} / 1.73 \mathrm{~m}^{2}\right)$ & $48.1 \pm 11.5$ & $41.9 \pm 11.5$ & 0.0744 \\
\hline $\mathrm{TC}(\mathrm{mg} / \mathrm{dL})$ & $173.8 \pm 28.7$ & $177.0 \pm 24.3$ & 0.7260 \\
\hline HDL-C (mg/dL) & $54.5 \pm 28.1$ & $51.1 \pm 16.2$ & 0.9820 \\
\hline LDL-C (mg/dL) & $85.2 \pm 22.6$ & $90.5 \pm 23.7$ & 0.3547 \\
\hline $\mathrm{TG}(\mathrm{mg} / \mathrm{dL})$ & $161.2 \pm 74.9$ & $190.6 \pm 86.8$ & 0.2888 \\
\hline $\mathrm{Alb}(\mathrm{g} / \mathrm{dL})$ & $4.0 \pm 0.4$ & $3.7 \pm 0.6$ & 0.3720 \\
\hline $\mathrm{K}(\mathrm{mEq} / \mathrm{L})$ & $4.3 \pm 0.5$ & $4.3 \pm 0.4$ & 0.8496 \\
\hline $\mathrm{Hb}(\mathrm{g} / \mathrm{dL})$ & $13.5 \pm 2.1$ & $12.5 \pm 1.3$ & 0.0647 \\
\hline $\mathrm{Ht}(\%)$ & $40.0 \pm 6.1$ & $34.7 \pm 9.1$ & 0.0545 \\
\hline HbAlc (NGSP) (\%) & $6.3 \pm 0.7$ & $6.5 \pm 0.9$ & 0.4491 \\
\hline
\end{tabular}

Table 2: Comparison of baseline between Low PP group and High PP group in CKD stage G3a-G3b.

Values are mean \pm standard deviation where appropriate. 
Citation: Kose E, An T, Kikkawa A (2018) The Relevance of High Pulse Pressure and Renal Function in Patients with Chronic Kidney Disease: Analysis for each Stage of Chronic Kidney Disease. Int J Clin Pharmacol Pharmacother 3: 137. doi: https://doi.org/10.15344/2456-3501/2018/137

Page 3 of 5

Table 2 compares the patient background characteristics and clinical laboratory data of the Low PP group and High PP group in CKD stage G3a-G3b. Significant differences were present for SBP, ALT, and BUN.

Table 3 shows patient background characteristics and clinical laboratory data between the Low PP group and the High PP group in CKD stage G4-G5. Significant differences were present for SBP, BUN, SCr, Ccr, eGFR, K, Hb, and Ht.

In the Low PP group, BUN and SCr significantly increased 12 months later from the baseline in CKD stage G4-G5. Conversely, Ccr and eGFR significantly decreased during the same period in CKD stage G4-G5. However, BUN, SCr, Ccr, and eGFR were not significantly different in the Low PP group in CKD stage G3a-G3b.

\begin{tabular}{|c|c|c|c|}
\hline Characteristics & $\begin{array}{l}\text { Low PP } \\
\text { group } \\
(\mathrm{n}=26)\end{array}$ & $\begin{array}{c}\text { High PP } \\
\text { group } \\
(\mathrm{n}=20)\end{array}$ & $\mathrm{p}$ value \\
\hline Age (y) & $66.6 \pm 12.2$ & $70.6 \pm 9.5$ & 0.2349 \\
\hline Gender $\mathrm{n}(\%)$ & & & 0.7957 \\
\hline Male & $14(53.9 \%)$ & $10(50.0 \%)$ & \\
\hline Female & $12(46.2 \%)$ & $10(50.0 \%)$ & \\
\hline Body weight $(\mathrm{kg})$ & $58.4 \pm 13.4$ & $60.8 \pm 13.0$ & 0.5915 \\
\hline Body mass Index $\left(\mathrm{kg} / \mathrm{m}^{2}\right)$ & $22.7 \pm 6.1$ & $23.7 \pm 4.3$ & 0.7399 \\
\hline Smoking history $\mathrm{n}(\%)$ & $10(50.0 \%)$ & $15(57.7 \%)$ & 0.6036 \\
\hline \multicolumn{4}{|l|}{ Comorbidity } \\
\hline Diabetes Mellitus n (\%) & $7(26.9 \%)$ & $11(55.0 \%)$ & 0.0531 \\
\hline Hypertension $\mathrm{n}(\%)$ & $19(73.1 \%)$ & $19(95.0 \%)$ & 0.0518 \\
\hline \multicolumn{4}{|l|}{ Clinical laboratory data } \\
\hline $\mathrm{SBP}(\mathrm{mmHg})$ & $125.5 \pm 10.4$ & $149.2 \pm 14.1$ & $<.0001$ \\
\hline DBP (mmHg) & $73.7 \pm 8.1$ & $70.2 \pm 10.5$ & 0.2487 \\
\hline AST (IU/L) & $21.9 \pm 5.9$ & $19.5 \pm 5.6$ & 0.1952 \\
\hline $\operatorname{ALT}(\mathrm{IU} / \mathrm{L})$ & $16.7 \pm 7.8$ & $15.8 \pm 8.5$ & 0.7226 \\
\hline SUA $(\mathrm{mg} / \mathrm{dL})$ & $7.6 \pm 1.7$ & $7.2 \pm 1.6$ & 0.4205 \\
\hline BUN (mg/dL) & $39.1 \pm 16.1$ & $56.6 \pm 18.2$ & 0.0013 \\
\hline $\mathrm{SCr}(\mathrm{mg} / \mathrm{dL})$ & $3.2 \pm 2.1$ & $4.4 \pm 2.3$ & 0.0135 \\
\hline $\mathrm{Ccr}(\mathrm{mL} / \mathrm{min})$ & $23.3 \pm 12.3$ & $14.1 \pm 6.3$ & 0.0117 \\
\hline eGFR $\left(\mathrm{mL} / \mathrm{min} / 1.73 \mathrm{~m}^{2}\right)$ & $18.9 \pm 8.4$ & $12.4 \pm 5.5$ & 0.0048 \\
\hline $\mathrm{TC}(\mathrm{mg} / \mathrm{dL})$ & $173.8 \pm 37.4$ & $187.2 \pm 55.0$ & 0.4073 \\
\hline $\mathrm{HDL}-\mathrm{C}(\mathrm{mg} / \mathrm{dL})$ & $49.9 \pm 19.3$ & $45.3 \pm 16.8$ & 0.5229 \\
\hline $\mathrm{LDL}-\mathrm{C}(\mathrm{mg} / \mathrm{dL})$ & $77.5 \pm 23.7$ & $98.0 \pm 46.5$ & 0.0611 \\
\hline $\mathrm{TG}(\mathrm{mg} / \mathrm{dL})$ & $3.7 \pm 0.6$ & $3.6 \pm 0.6$ & 0.2205 \\
\hline $\mathrm{Alb}(\mathrm{g} / \mathrm{dL})$ & $192.6 \pm 161.1$ & $143.6 \pm 55.9$ & 0.7367 \\
\hline $\mathrm{K}(\mathrm{mEq} / \mathrm{L})$ & $4.4 \pm 0.5$ & $4.9 \pm 0.6$ & 0.0067 \\
\hline $\mathrm{Hb}(\mathrm{g} / \mathrm{dL})$ & $11.5 \pm 1.4$ & $9.7 \pm 1.3$ & $<.0001$ \\
\hline $\mathrm{Ht}(\%)$ & $34.3 \pm 4.2$ & $29.6 \pm 4.2$ & 0.0008 \\
\hline HbAlc (NGSP) (\%) & $6.1 \pm 1.2$ & $6.2 \pm 0.9$ & 0.7471 \\
\hline
\end{tabular}

Table 3: Comparison of baseline between Low PP group and High PP group in CKD stage G4-G5.

Values are mean \pm standard deviation where appropriate.
In the High PP group, BUN and SCr significantly increased 12 months later from the baseline in CKD stage G4-G5. Conversely, Ccr and eGFR significantly decreased during the same period in CKD stage G4-G5. However, BUN, SCr, Ccr, and eGFR were not significantly different in the High PP group in CKD stage G3a-G3b (Table 4).

Changes in renal function at CKD stage G4-G5 between the Low PP group and the High PP group were compared for one year from the baseline. $\triangle \mathrm{BUN}$ and $\triangle \mathrm{SCr}$ significantly increased in the High PP group compared to the Low PP group. $\triangle$ eGFR was significantly decreased in the High PP group compared to the Low PP group (Table 5).

\section{Discussion}

The most important finding of the present study is that renal function may be worse in the High PP group compared to the Low PP group for CKD stage G4-G5. Therefore, it is important to pay attention to PP management to prevent the decline of renal function. More specifically, blood pressure (BP) should be managed on a daily basis along with improvement in lifestyle. Factors including diet, exercise, and smoking cessation should be managed because increased PP is caused by systolic hypertension.

In our previous study, we showed that CKD patients were more likely to have increased PP and were associated with the reduction of renal function [9]. In recent years, a few reports showed that stage classification focused on GFR is associated with the onset of CVD, deterioration of renal prognosis, and life prognosis $[2,10]$. In this context, the present study examined the association between increased $\mathrm{PP}$ and renal function according to each CKD stage classification for CKD patients.

There were no significant differences in renal function between the baseline and at one year in CKD stage G3a-G3b in both the Low PP group and the High PP group. However, in CKD stage G4-G5, renal function significantly decreased 12 months later compared to the baseline, and renal function was worsened in the High PP group compared to the Low PP group. In addition, in univariate analysis, there was no significant deterioration of renal function in CKD stage G3a-G3b, but renal function worsened in the High PP group compared to the Low PP group at CKD stage G4-G5 (see Table 2 and Table 3). These findings may help to explain that arteriosclerosis does not significantly affect renal function in CKD stage G3aG3b but significantly worsens renal function at CKD stage G4-G5. Otsuka et al. examined the relationship between lower eGFR and increased risk of arteriosclerosis in accordance with each stage of the classification of diabetic nephropathy in diabetic patients [12]. Several arteriosclerosis-related indicators deteriorated in both Stage 2 (incipient nephropathy; $30-300 \mathrm{mg} /$ day or $/ \mathrm{gCr}$ in albuminuria) and Stage 3 (overt nephropathy; $300 \mathrm{mg} /$ day or gCr in albuminuria or 0.5 $\mathrm{g} /$ day or $\mathrm{gCr}$ in proteinuria) compared to Stage 1 (pre-nephropathy; $<30 \mathrm{mg}$ /day or /gCr in albuminuria). Furthermore, they categorized eGFR into a lowering group and a non-lowering group according to each stage of diabetic nephropathy classification, and examined the arteriosclerotic index, PWV. PWV was significantly elevated in the eGFR lowering group in diabetic nephropathy stage 1 and stage 2 [12]. These findings may help to explain that as the stage of diabetic nephropathy progresses, arteriosclerosis deteriorates. As is evident from the above, the findings of the present study are consistent with those of the previous study [12]. In this regard, we believe it is indispensable to control PP for the management of advanced CKD. 
Citation: Kose E, An T, Kikkawa A (2018) The Relevance of High Pulse Pressure and Renal Function in Patients with Chronic Kidney Disease: Analysis for each Stage of Chronic Kidney Disease. Int J Clin Pharmacol Pharmacother 3: 137. doi: https://doi.org/10.15344/2456-3501/2018/137

Page 4 of 5

On the mechanism of increased SBP with the progression of arteriosclerosis, part of the blood ejected from the heart is sent directly to the periphery and part of it is stored in an elastic blood vessel like the aorta and sent to the periphery in diastole. However, when vascular elasticity decreases because of arteriosclerosis, the volume of blood from the periphery at systole increases and SBP increases because of which DBP decreases as the volume of blood sent in diastole is reduced. Therefore, if increase in SBP is observed in advanced CKD patients, a corresponding progression of arteriosclerosis and change in BP should also be noted.

On the contrary, in predialysis patients with $\mathrm{CKD}$, comprehensive management that is aimed at suppressing disease pathology, particularly BP management, is important. The significance of hypotensive action in CKD is the suppression of CKD progression, and reduction risk of the onset of CVD and death. Meta-analysis revealed that the decrease in the rate of GFR slows as BP reaches $130 / 80 \mathrm{mmHg}$ in clinic BP [13]. In addition, the risk of CVD is the lowest around SBP $130 \mathrm{mmHg}$ after pressure reduction in intervention studies of CVD high-risk patients [14]. Therefore, drug therapy and lifestyle intervention is required so that clinic BP can be controlled to be $130 / 80 \mathrm{mmHg}$ or less. In predialysis patients with $\mathrm{CKD}$, in addition to BP management, lifestyle including excessive intake of energy or salt, insufficient exercise, drinking, smoking, and stress are also related to the progress of CKD. Improvement in lifestyle forms the basis for CKD treatment. Metabolic syndrome, especially overeating and insufficient exercise, is closely related with CKD progression and CVD onset; however, drug therapy or the acquisition of knowledge regarding disease pathology and improvements in lifestyle may prevent severity because of complications. Education hospitalization for patients with CKD is considered effective for the prevention of severity [15]. Patients will be able to self-control by acquiring the knowledge necessary for the prevention of severity and improving lifestyle through educational hospitalization for CKD. Early rehospitalization rate was suppressed by $36.2 \%$ because of the instruction of multidisciplinary medical teams including physicians, pharmacists, nurses, and dietitians compared to the individual medical specialists at CKD educational hospitalization in our previous study [16]. Taken together, treatment by a multidisciplinary medical team is important for CKD educational hospitalization in predialysis patients with CKD.

The present study has several limitations. First, this was a singlecenter cross-sectional study with a small sample size. Second, patients with diabetes mellitus were included; it is possible that some decrease in eGFR in these patients was the result of glomerulonephritis because of diabetic nephropathy. Third, BP was measured at home; there is a circadian variation in BP, BP may be elevated in clinical settings, and also varies depending on the method or time of measurement [17]. Because this study was retrospective we could not address these issues, the abovementioned factors may have affected the results of this study. In future studies, BP should be measured using ambulatory BP monitoring that is closely associated with the degree of hypertensive organ damage [18-20].

The present study has several limitations. First, this was a singlecenter cross-sectional study with a small sample size. Second, patients with diabetes mellitus were included; it is possible that some decrease

\begin{tabular}{|c|c|c|c|c|c|c|}
\hline \multicolumn{7}{|l|}{ (A) Low PP Group } \\
\hline & \multicolumn{3}{|c|}{ CKD stage G3a-G3b $(n=42)$} & \multicolumn{3}{|c|}{ CKD stage G4-G5 $(n=26)$} \\
\hline Renal function & baseline & 12 months later & $\mathrm{p}$ value & Baseline & 12 months later & $\mathrm{p}$ value \\
\hline BUN (mg/dL) & $21.2 \pm 5.6$ & $19.5 \pm 6.7$ & 0.0537 & $34.1 \pm 13.9$ & $39.1 \pm 16.2$ & 0.0435 \\
\hline $\mathrm{SCr}(\mathrm{mg} / \mathrm{dL})$ & $1.2 \pm 0.3$ & $4.2 \pm 2.0$ & 0.5797 & $2.7 \pm 1.6$ & $3.2 \pm 2.1$ & 0.0029 \\
\hline $\operatorname{Ccr}(\mathrm{mL} / \mathrm{min})$ & $57.2 \pm 17.3$ & $58.4 \pm 23.4$ & 0.6872 & $28.1 \pm 18.8$ & $23.3 \pm 12.3$ & 0.0024 \\
\hline eGFR $\left(\mathrm{mL} / \mathrm{min} / 1.73 \mathrm{~m}^{2}\right)$ & $46.9 \pm 9.3$ & $48.1 \pm 11.5$ & 0.4261 & $22.7 \pm 11.3$ & $18.9 \pm 8.4$ & 0.0014 \\
\hline \multicolumn{7}{|l|}{ (B) High PP Group } \\
\hline & \multicolumn{3}{|c|}{ CKD stage G3a-G3b $(n=16)$} & \multicolumn{3}{|c|}{ CKD stage G4-G5 $(\mathrm{n}=20)$} \\
\hline Renal function & baseline & 12 months later & $\mathrm{p}$ value & baseline & 12 months later & $\mathrm{p}$ value \\
\hline BUN $(\mathrm{mg} / \mathrm{dL})$ & $23.6 \pm 8.4$ & $23.8 \pm 8.5$ & 0.7871 & $43.3 \pm 15.4$ & $56.6 \pm 18.2$ & 0.0069 \\
\hline $\mathrm{Scr}(\mathrm{mg} / \mathrm{dL})$ & $1.2 \pm 0.4$ & $1.3 \pm 0.4$ & 0.1318 & $3.0 \pm 1.2$ & $4.4 \pm 2.3$ & 0.0006 \\
\hline $\mathrm{CCr}(\mathrm{mL} / \mathrm{min})$ & $52.5 \pm 13.9$ & $50.8 \pm 15.7$ & 0.3226 & $21.0 \pm 10.0$ & $14.1 \pm 6.3$ & 0.0011 \\
\hline eGFR $\left(\mathrm{mL} / \mathrm{min} / 1.73 \mathrm{~m}^{2}\right)$ & $43.9 \pm 9.9$ & $41.9 \pm 11.5$ & 0.2987 & $18.6 \pm 9.0$ & $12.3 \pm 5.5$ & 0.0004 \\
\hline
\end{tabular}

Table 4: Effect of renal function for each CKD stage between Low PP group and High PP group.

Values are mean \pm standard deviation where appropriate.

\begin{tabular}{|l|c|c|c|}
\hline Change in Renal function & Low PP group $(\mathrm{n}=26)$ & High PP group $(\mathrm{n}=20)$ & $\mathrm{p}$ value \\
\hline$\Delta \mathrm{BUN}(\mathrm{mg} / \mathrm{dL})$ & $5.0 \pm 3.1$ & $13.3 \pm 3.4$ & 0.0373 \\
\hline$\Delta \mathrm{Scr}(\mathrm{mg} / \mathrm{dL})$ & $0.53 \pm 1.0$ & $1.5 \pm 1.8$ & 0.0084 \\
\hline$\Delta \mathrm{Ccr}(\mathrm{mL} / \mathrm{min})$ & $-4.8 \pm 1.8$ & $-6.9 \pm 2.2$ & 0.0756 \\
\hline$\Delta \mathrm{eGFR}\left(\mathrm{mL} / \mathrm{min} / 1.73 \mathrm{~m}^{2}\right)$ & $-2.9 \pm 4.4$ & $-6.2 \pm 6.4$ & 0.0481 \\
\hline
\end{tabular}

Table 5: Effect of Renal function for CKD stage G4-G5 between Low PP group and High PP group.

Values are mean \pm standard deviation where appropriate.

$\triangle \mathrm{BUN}, \triangle \mathrm{SCr}, \Delta \mathrm{Ccr}$, and $\triangle \mathrm{eGFR}$ show the chane in renal function for one year from baseline. 
Citation: Kose E, An T, Kikkawa A (2018) The Relevance of High Pulse Pressure and Renal Function in Patients with Chronic Kidney Disease: Analysis for each Stage of Chronic Kidney Disease. Int J Clin Pharmacol Pharmacother 3: 137. doi: https://doi.org/10.15344/2456-3501/2018/137

Page 5 of 5

in eGFR in these patients was the result of glomerulonephritis because of diabetic nephropathy. Third, BP was measured at home; there is a circadian variation in BP, BP may be elevated in clinical settings, and also varies depending on the method or time of measurement [17]. Because this study was retrospective we could not address these issues, the abovementioned factors may have affected the results of this study. In future studies, BP should be measured using ambulatory BP monitoring that is closely associated with the degree of hypertensive organ damage [18-20].

In conclusion, although there were no significant differences in renal function between the High PP group and the Low PP group in CKD stage G3a-G3b, renal function deteriorated between both groups in CKD stage G4-G5, and deteriorated more in the High PP group. Therefore, the decrease in renal function may be reflected in the CKD stage in which arteriosclerosis has progressed.

\section{Acknowledgement}

The authors thank the manager of Yokosuka Kyousai Hospital who provided permission for conducting this study.

\section{Competing Interests}

The authors declare that they have no competing interests.

\section{References}

1. Japan nephrology society (2012) Clinical Practice Guidebook for Diagnosis and Treatment of Chronic Kidney Disease 2012. Nihon Jinzo Gakkai Shi 54: 1034-1191.

2. Go AS, Chertow GM, Fan D, McCulloch CE, Hsu CY, et al. (2004) Chronic kidney disease and the risks of death, cardiovascular events, and hospitalization. N Engl J Med 351: 1296-1305.

3. Keith DS, Nichols GA, Gullion CM, Brown JB, Smith DH, et al. (2004) Longitudinal follow-up and outcomes among a population with chronic kidney disease in a large managed care organization. Arch Intern Med 164 659-663.

4. Brenner BM, Meyer TW, Hostetter TH (1982) Dietary protein intake and the progressive nature of kidney disease: the role of hemodynamically mediated glomerular injury in the pathogenesis of progressive glomerular sclerosis in aging, renal ablation, and intrinsic renal disease. N Engl J Med 307: 652-659.

5. Schaeffner ES, Kurth T, Curhan GC, Glynn RJ, Rexrode KM, et al. (2003) Cholesterol and the risk of renal dysfunction in apparently healthy men. $J$ Am Soc Nephrol 14: 2084-2091.

6. Otsuka A, Kubo S, Fukamizu H, Saito K, Shimomura A, et al. (2011) Risk of Arteriosclerosis Increase with Renal Function Decline in Case of Type 2 Diabetes with A Low Ankle-brachial Index. J Japan Diab Soc 52: 91-97.

7. Chamiot-Clerc P, Renaud JF, Safar ME (2011) Pulse pressure, aortic reactivity, and endothelium dysfunction in old hypertensive rats. Hypertension. 37: 313-321.

8. Safar ME, Levy BI, Struijker-Boudier H (2003) Current perspectives on arterial stiffness and pulse pressure in hypertension and cardiovascular diseases. Circulation 107: 2864-2869.

9. Kose E, An T, Kikkawa A, Matsumoto Y, Hayashi $H$, et al. (2016) The association between the increase in pulse pressure and renal function in chronic kidney disease patients with dyslipidemia. Pharmazie 71: 510-513

10. Levey AS, Eckardt KU, Tsukamoto Y, Levin A, Coresh J, et al. (2005) Definition and classification of chronic kidney disease: a position statement from Kidney Disease: Improving Global Outcomes (KDIGO). Kidney Int 67 2089-2100.

11. Asmar R, Vol S, Brisac AM, Tichet J, Topouchian J, et al. (2001) Reference values for clinic pulse pressure in a nonselected population. Am J Hypertens 14: 415-418.
12. Otsuka A, Ogiso Y, Murai K, Ichihara K (2009) Reduced Glomerular Filtration Rate Is Associated with an Increased Risk of Arteriosclerosis in Diabetic Patients: Analysis by Diabetic Nephropathy Stage. J Japan Diab Soc 52: 683-689.

13. Bakris GL, Williams M, Dworkin L, Elliott WJ, Epstein M, et al. (2000) Preserving renal function in adults with hypertension and diabetes: a consensus approach. National Kidney Foundation Hypertension and Diabetes Executive Committees Working Group. Am J Kidney Dis 36: 646661.

14. Sleight P, Redon J, Verdecchia P, Mancia G, Gao P, et al. (2009) Prognostic value of blood pressure in patients with high vascular risk in the Ongoing Telmisartan Alone and in combination with Ramipril Global Endpoint Trial study. J Hypertens 27: 1360-1369.

15. Yamaji K, Kurusu A, Okamoto M, Sekiguchi Y, Horikoshi S, et al. (2007) Effect of educational hospitalization on chronic kidney disease (CKD) patients. Clinical Nephrol 68: 401-404.

16. Kose E, An T, Kikkawa A, Hayashi H (2016) Early rehospitalization after initial chronic kidney disease educational hospitalization relates with a multidisciplinary medical team. J Pharm Health Care Sci 2: 27.

17. The Japanese society of Hypertension (2014) Guidelines for the management of hypertension.

18. Imai $Y$, Obara T, Asamaya $\mathrm{K}$, Ohkubo $\mathrm{T}$ (2013) The reason why home blood pressure measurements are preferred over clinic or ambulatory blood pressure in Japan. Hypertens Res 36: 661-672.

19. Sokolow M, Werdegar D, Kain HK, Hinman AT (1966) Relationship between level of blood pressure measured casually and by portable recorders and severity of complications in essential hypertension. Circulation 34: 279-298.

20. Mancia G, Zanchetti A, Agabiti-Rosei E, Benemio G, De Cesaris R, et al. (1997) Ambulatory blood pressure is superior to clinic blood pressure in predicting treatment-induced regression of left ventricular hypertrophy. SAMPLE Study Group. Study on Ambulatory Monitoring of Blood Pressure and Lisinopril Evaluation. Circulation 95: 1464-1470. 